\section{ESA airs itself}

Last week, the European Space Agency displayed

itself at the Farnborough

\section{Air Show in Britain. Allan Piper reports}

TN solid commercial terms, this year's 1 Farnborough International Air Show brought relatively little joy to the world's aerospace industries, with firm orders for hardware considerably down on recent years. To the many large corporations affected-companies such as Rolls-Royce and Westland from Britain, Aerospatiale and VFW-Fokker from Europe, and Boeing, Lockheed and McDonnell Douglas from the USthe cutback is no less unwelcome for all that it was expected and is seen as only temporary. But few of the contractors present will regard the latest Farnborough as a complete failure. In the first place, the long-term future of the aerospace industry seems secure enough, and this year's record crowds again proved the show's worth as a massive public relations exercise. Second, and far more important, the get-together encouraged a measure of serious discussion on what has become a vital issue for world aviation-international collaboration.

With the enormous expense now involved in the design and development of most civil and military aviation hardware, it is scarcely surprising that collaboration emerged very early during this year's show as the new watchword for aerospace. In Britain, attention focused particularly sharply on planned Anglo-US discussions announced by Gerald Kaufman, the UK Industry Minister.

But for the 12-nation European Space Agency (ESA), prominently represented at Farnborough, collaboration is an already well-established principle. Since its launching almost 16 months ago ESA has put no less than eight scientific satellites successfully into orbit, working with three giant consortia involving many of Europe's aerospace contractors.

While that prolific record itself speaks volumes for the success of European cooperation, early discussions on joint ESA-NASA ventures have ensured that broader collaboration will not go by the board either. The Spacelab project, already under way, represents ESA's largest scientific contribution to the NASA space shuttle programme, planned for the late 1970s and 1980s. Next month, ESA officials are expected to approve funds for another joint project with NASA, the Large Space Telescope. And many of the other new projects in the ESA pipeline will play important roles in forthcoming international programmes.

Meanwhile, Farnborough provided
ESA with an ideal opportunity to stamp its presence on the public's mind. Operating comfortably on a current annual budget of $\$ 600$ million, the agency has much to offer in the way of eyecatching space technology. Triumphs have already been notched up with the ESRO, HEOS and COS B satellite programmes, and ESA has an equally impressive timetable drawn up for the next four years or so. New ESA projects include:

- OTS, the Orbital Test Satellite, scheduled for launching in mid-1977. Primarily a demonstration model for the European Communications Satellites (ECS) programme, OTS is nonetheless adaptable for various missions. The basic service module can, for example, carry weather forecasting equipment just as effectively as a telecommunications payload. The first ope rational ECS's will provide around 5,000 telephone circuits and two wideband television channels along with data transmission and teleconferencing services. During Farnborough a $£ 900,000$ design contract for ECS-1 was placed with MESH, one of the European consortia.

- METEOSAT, a long range weather forecasting satellite, scheduled for launching next year. METEOSAT will provide Europe's contribution to the Global Atmospheric Research Programme and the World Meteorological Organisation's later World Weather Watch. It will also fit into a global coverage involving Japan, the Soviet Union and the US.

- GEOS, the world's first scientific geostationary satellite, will monitor the magnetosphere. Scheduled for launching next year, it will play a major role in the International Magnetospheric Programme.

- IUE, the International Ultraviolet Explorer, a joint venture between NASA, the UK Science Research Council, and ESA, to be launched next year. ESA will contribute the solarcell array for the satellite, and will design, build and operate the ground station near Madrid in Spain.

- ISEE-B, the International Sun-Earth Explorer, part of another NASA-ESA collaborative project. ESA's ISEE-B will be launched in tandem with NASA's ISEE-A next autumn.

- MAROTS, a shipping communications satellite scheduled for launching early in 1978. The payload will sit on an OTS service module.

- AEROSAT, an aeronautical satellite for ground to air communications on

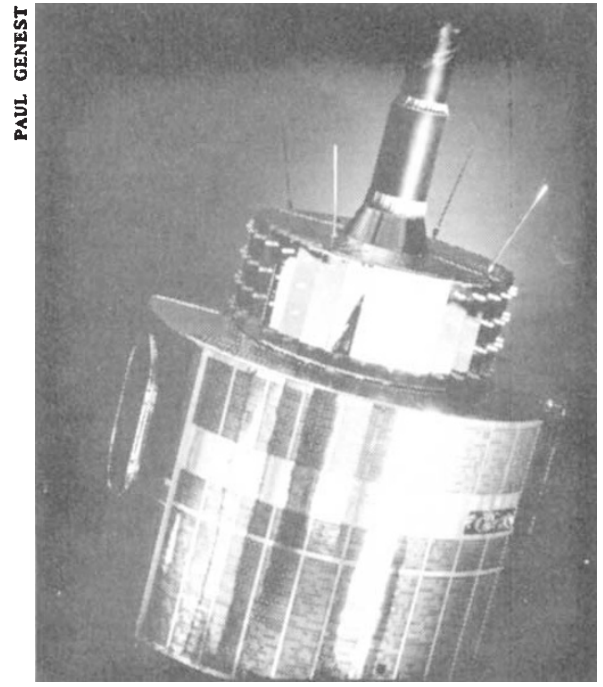

\section{METEOSAT}

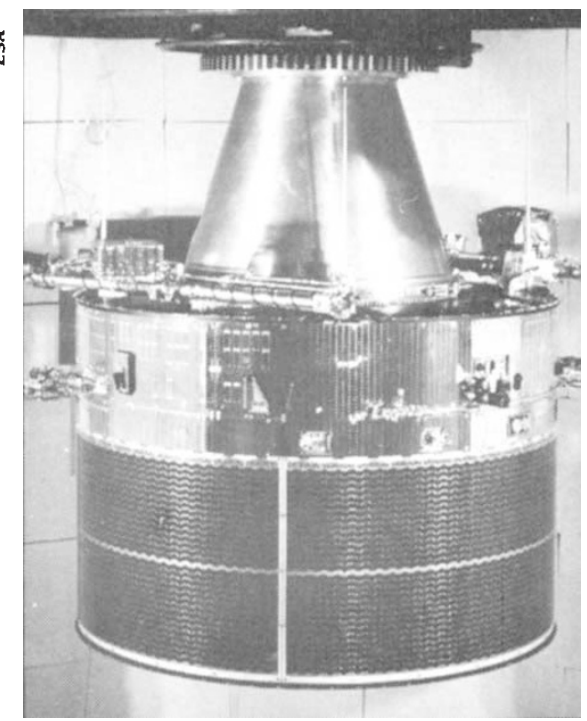

GEOS

Earth. Two AEROSATs will be launched into geostationary orbit at the end of 1979 and beginning of 1980 .

- EXOSAT, an X-ray astronomy satellite that will monitor cosmic X-ray sources. Along with GEOS, IUE and ISEE-B, EXOSAT will be a purely scientific spacecraft. It will be launched in 1980 .

- Spacelab, the star of them all. A re-usable pressurised space laboratory, Spacelab will house scientists and enginecrs working in shirtsleeve comfort. A major component of NASA's space shuttle programme, it will become operational during the 1980s.

- Increasing congestion in the international queue for NASA's launching facilities, which is likely to become worse as NASA steps up its own requirements, has led ESA to develop a heavy launcher, Ariane, for itself. Designed to lift satellites weighing around $800 \mathrm{~kg}$, it could prove crucial to the ECS programme. Ariane's four qualification shots, planned for 1979 and 1980 , will be from the permanent launching base in French Guiana. 